\title{
Desempenho de Ovinos Bergamácia na Região de Brasília ${ }^{1}$ \\ Roberto Meirelles de Miranda², Concepta McManus²
}

\begin{abstract}
RESUMO - Dados colhidos de 1982 a 1999, em Brasília, DF, sobre 1102 ovinos da raça Bergamácia Brasileira foram analisados para obter informações sobre seu comportamento na região. A média geral de intervalo de partos foi 337,94 $\pm 109,34$, mas, nos anos de monta contínua, 282,91 dias. A fertilidade das ovelhas foi de 90,13\%, a frequência de partos duplos, 12,63\% e a de partos triplos, negligível. A relação entre sexos foi de 1:1. Ocorreram nascimentos em todos os meses do ano. A idade média ao primeiro parto foi de 588,58 565,31 dias. As médias de pesos ao nascer e aos 3, 6 e 12 meses de idade foram altamente influenciadas pelo sexo, ano e mês de nascimento e tipo de parto. A mortalidade atingiu 6,62\% até 4 dias de idade e 22,96\% de 5 a 90 dias e foi altamente dependente do ano de nascimento, tipo de parto e peso ao nascer. A produção de lã foi de $1,28 \mathrm{~kg}$. A segunda e a terceira tosquias foram as de maior produção. Amostras de lã tiveram diâmetros de 30,8 e 38,0 micra, com alto coeficiente de variação. O rebanho avaliado não atendeu, em características produtivas, aos padrões raciais italiano e brasileiro, mas atingiu produtividade comparável à dos ovinos deslanados tropicais criados no Brasil.
\end{abstract}

Palavras-chave: crescimento, mortalidade, produção de lã, reprodução

\section{Performance of Bergamasca Sheep in the Brasília Region}

\begin{abstract}
Data collected from 1982 to 1999, in Brasília, DF, Brazil, on 1102 head of Brazilian Bergamasca sheep were analyzed to obtain information on performance of the breed in the region. Average lambing interval was 337.94 \pm 109.4 , but under continuous mating, the average lowered to 282.1 days. Ewe lambing rate was $90.13 \%$, frequency of twins $12.63 \%$, number of triplets negligible and sex ratio 1:1. Lambing occurred in all months of the year. Age at first lambing was 588.58 \pm 65.31 days. Average birth, 3, 6 and 12 -month weights were highly influenced by sex, year and month of birth and lambing type. Mortality from birth to 4 days of age was $6.62 \%$ and from 5 days to $90,22.96 \%$, and was highly dependent upon the year of birth, lambing type and birth weight. Average fleece weight production was $1.28 \mathrm{~kg}$ and the highest fleece weights were obtained in the second and third shearing. Samples of wool diameter averaged 30.8 and 38.0 micra, with high coefficient of variation. The flock does not conform to the racial standards defined in Italy and Brazil for productive parameters but it reached similar levels to those of the hair sheep breeds raised in the Brazilian tropics.
\end{abstract}

Key Words: growth, mortality, wool production, reproduction

\section{Introdução}

A criação de ovinos no Brasil concentrou-se nas regiões Sul e Nordeste com, respectivamente, 55 e $37 \%$ da população. O Centro-Oeste possui somente 2,6\% do efetivo ovino do país (INSTITUTO BRASILEIRO DE GEOGRAFIA E ESTATÍSTICAIBGE,1997). A pesquisa e os resultados publicados também trataram, principalmente, dos problemas das duas regiões mais importantes. Poucos trabalhos, no Brasil, estudaram o comportamento de ovinos durante longos períodos. São de valor histórico os trabalhos pioneiros de SANTIAGO e PAULIN NETO (1954 e 1954a) e JARDIM et al. (1956), com pequeno número de animais, na região de São Paulo. Recentemente, pesquisadores do Centro Nacional de Pesquisa em Caprinos, no Ceará, passaram a publicar resultados de experimentos de maior duração, com raças de ovinos deslanados (LIMA, 1983; FERNANDES et al., 1993; e SILVA et al., 1995).

Os trabalhos publicados na literatura internacional referem-se a condições de criação e raças totalmente diferentes das existentes em Brasília e, assim, servem somente para comparações (BODISCO et al., 1973; COMBELLAS, 1980).

A raça Bergamácia, introduzida no Brasil na década de 30, foi aos poucos substituída, na preferência dos criadores, por ovinos deslanados. Nos últimos tempos, entretanto, tem-se despertado o interesse pela raça, que volta a aparecer em trabalhos de Universidades (MACEDO et al., 1996). A raça, na origem, é notável pela produção de carne e, como produtora de lã, alcança $5,5 \mathrm{~kg}$ nos machos e $4,5 \mathrm{~kg}$ nas fêmeas, em regime de duas tosquias anuais. 
Este trabalho visa divulgar os dados obtidos de 1982 a 1999, fornecendo informações sobre o comportamento de ovinos Bergamácia no ambiente de Brasília, bem diferente da região de origem da raça, a Itália (ASSOCIAZIONE NAZIONALE DELLA PASTORIZIA, 1984). As informações servirão de base para decisões sobre escolha da raça e detalhes do padrão racial e em relação às expectativas da ovinocultura na região central do Brasil.

\section{Material e Métodos}

O experimento, iniciado em 1982, continua em execução na fazenda da Universidade de Brasília, localizada junto à cidade, em altitude de $1158 \mathrm{~m} \mathrm{e}$ latitude de $15^{\circ} 47^{\prime}$ Sul. O clima da região é tropical chuvoso com estação seca, longa e bem definida, de maio a setembro; a temperatura média é de $21,2^{\circ}$; a média das máximas é de $26,6^{\circ}$ e das mínimas, de $15,9^{\circ}$; a temperatura máxima absoluta é de $34,5^{\circ}$ e a mínima absoluta, de $1,6^{\circ}$; a umidade relativa média é de $67 \%$; e a precipitação anual média, de $1552,1 \mathrm{~mm}$, concentrada nos meses de outubro a abril.

Os animais estudados são remanescentes dos ovinos Bergamácia importados da Itália na década de 30 e localizados, inicialmente, no Estado da Bahia. Nesta região, foram mantidos sujeitos a cruzamentos com os ovinos locais. Assim, os animais podem ser definidos, mais precisamente, como de sangue predominantemente Bergamácia.

Orebanho, durante os primeiros anos, foi mantido em regime extensivo, em pastos de Andropogon gayanus, variedade bisquamulatus e Paspalum saurae, recebendo pequena suplementação de silagem de milho ou capim ou cana cortada durante a seca; mistura mineral completa ficou disponível todo o tempo. Nos últimos anos, com o risco de predadores, o rebanho passou a ficar preso de $17 \mathrm{~h}$ às $8 \mathrm{~h} 30$. No período de 1995 a 1999, o rebanho passou a receber suplementação de concentrado durante a seca, no último mês próximo ao parto e durante a lactação.

Nos primeiros anos do experimento, o rebanho foi mantido como um só lote, machos e fêmeas de todas as idades permanentemente juntos. A reprodução era, assim, ao acaso, machos e fêmeas iniciavam a vida reprodutiva ao atingir a puberdade. A partir de 1984, os sexos passaram a ser separados, com todas as fêmeas acasaladas com um macho de cada vez. No fim de 1987, foi estabelecido o regime de estação de monta de duração limitada com grupos de fêmeas de um ou mais anos de idade e machos individuais.
O controle sanitário do rebanho consistiu em aplicação de vermífugos, vacinações contra febre aftosa e clostridioses e tratamento de miíases e de casos de fotossensibilização, muito comuns nos anos iniciais do experimento.

O rebanho foi revisado diariamente e todas as alterações, anotadas. Pesagens foram feitas a cada 14 dias durante o tempo em que o animal permanece no rebanho. Datas de estação de monta, nascimentos e mortes foram sistematicamente registradas. Os cordeiros, ao nascer, receberam número tatuado na orelha e gravado em um placa colocada em colar no pescoço, para pronta identificação. O número da mãe foi anotado. O rebanho foi tosquiado anualmente, realizando-se duas avaliações da qualidade da lã, a primeira no Secretariado Uruguayo de la Lana, em Montevidéo, e a segunda, na Cooperativa de Lãs Vale do Uruguai, em Uruguaiana.

Todas as informações foram registradas em fichas individuais e passadas para planilhas do Excel.

Neste trabalho foram analisados os dados relativos a 1102 nascimentos ocorridos nos 17 anos de controle.

A análise estatística foi feita usando os procedimentos GLM, CORR e teste de qui-quadrado do Statistical Analysis System (SAS/STAT, 1990). Os efeitos examinados foram sexo, ano e mês de nascimento, idade da mãe ao parto, ordem de parição, tipo de parto, ordem, ano e mês da tosquia e as covariáveis peso ao nascer, à desmama e aos 12 meses de idade, quando apropriadas.

\section{Resultados e Discussão}

\section{Reprodução}

A média de 697 intervalos entre partos (IEP) foi de 337,94, com desvio padrão de 109,34 dias enquanto COSTA et al. (1990) obtiveram 251,47 dias, com ovelhas Morada Nova, no Estado de São Paulo e COMBELLAS (1980) apresentou o valor 247 dias para ovinos tropicais em geral. Em regime de monta contínua, usado nos primeiros anos do trabalho, a média de IEP foi de 282,91 dias, indicando maior eficiência reprodutiva para este regime. Nos anos seguintes, a fixação de estações de monta anuais, prolongando artificialmente os intervalos entre parto, contribuiu, certamente, para a elevação da média geral. A comparação entre anos foi altamente significativa $(\mathrm{P}<0,01)$, em grande parte devido à diferença de regimes de monta. Ao longo do tempo, houve pequeno aumento do IEP, traduzido na correlação $+0,24(\mathrm{P}<0,01)$ entre o número de dias e ano. A idade 
Rev. bras. zootec.

da ovelha exerceu desprezível efeito sobre o IEP, pois a correlação, apesar de altamente significativa $(\mathrm{P}<0,01)$, foi somente de $+0,11$. O tipo de parto simples ou múltiplo - não teve efeito sobre o intervalo seguinte. COSTA et al. (1990) também verificaram diferenças significativas entre anos, mas, diferindo dos resultados aqui apresentados, constatara, influência do tipo de parto, os duplos diminuindo o intervalo. A fertilidade (número de ovelhas paridas x 100/ número de ovelhas acasaladas) foi de $90,13 \%$ e a fecundidade (número de cordeiros nascidos x 100/ número de ovelhas acasaladas), de 98,14\%. Estes resultados superaram os de FIGUEIREDO et al. (1979), obtidos com a raça Santa Inês, mas foram inferiores aos apresentados por LIMA (1983), com esta raça. Durante todo o experimento, a frequiência de partos duplos foi de $12,63 \%$ e a de triplos, baixíssima, $0,31 \%$, resultando em prolificidade (tamanho médio da ninhada) de 1,13. Este resultado contrasta com a afirmação, presente em várias fontes (ARCO, 1999; ASSOCIAZIONE..., 1984), de que a raça Bergamácia tem elevada prolificidade, com altas frequências de partos múltiplos. A frequência de partos múltiplos foi altamente influenciada $(\mathrm{P}<0,01)$ pelo ano de nascimento e pela ordem de parição. A variação entre anos foi errática, mas, na sucessão de partos, notou-se sensível aumento após a segunda parição, atingindo o máximo na sétima. A relação entre sexos foi de, exatamente, 1:1. Ocorreram nascimentos em todos os meses do ano, demonstrando que a raça, apesar de originária de clima temperado, tem, no Brasil, comportamento poliestral, como as raças deslanadas.

A idade média ao primeiro parto foi de 588,58 dias, com desvio-padrão de 65,31 dias, e variou fortemente com o ano de nascimento $(\mathrm{P}<0,01)$, diferenciando-se o período 1982-83, de monta contínua com fêmeas de todas as idades no mesmo lote, com média de 579,16 dias.

\section{Desenvolvimento ponderal}

As médias dos pesos alcançados ao nascer e aos 3, 6 e 12 meses de idade e sua variação conforme o tipo de parto são apresentadas na Tabela 1 .

Os pesos ao nascer, em conjunto, tiveram coeficiente de variação de $20,60 \%$ e os pesos aos 3,6 e 12 meses, 18,49; 16,92; e 17,42, respectivamente. Houve, assim, redução da variação, determinada, possivelmente, pela saída, por morte, de animais fracos e com baixo peso e desenvolvimento. Por outro lado, a grande variação observada pode ser atribuída ao fato de todos animais terem sido mantidos no rebanho até a idade de um ano. Os efeitos de sexo, ano, mês de nascimento e tipo de parto foram altamente significativos $(\mathrm{P}<0,01)$ sobre todos os pesos. Outros autores, no Brasil, verificaram a influência destes fatores, FERNANDES et al. (1993), em relação a tipo de parto; FIGUEIREDO et al. (1985), quanto ao ano de nascimento e tipo de parto; COSTA et al. (1990), para sexo e ano de nascimento; SILVA et al. (1998), para sexo, ano de nascimento e tipo de parto; e RODA et al. (1995), para sexo e ano de nascimento. Os dados deste trabalho não indicaram efeito da idade da mãe, contrastando com resultados de FERNANDES et al. (1985a) e RODA et al. (1995), que encontraram efeitos altamente significativos da idade da mãe sobre pesos. Os machos foram sempre mais pesados que as fêmeas.

Ao longo dos anos, observou-se, inicialmente, aumento dos pesos médios em todas as idades, seguido, na década de 90 , de estabilização dos pesos ao nascer e queda das médias aos 3, 6 e 12 meses. Esta redução coincidiu com a prática da prisão dos animais à noite, medida tomada em virtude do ataque de cães, que impossibilitou o pastejo noturno.

A influência do mês de nascimento sobre os pesos variou com a idade observada. Os pesos ao nascer e aos três meses tiveram valores mínimos nos nascimentos nos meses de seca e máximos nos meses de novembro, dezembro e janeiro, coincidindo com o final da gestação e os primeiros meses de vida com bons pastos. Os animais nascidos no início do ano completaram seis meses de idade em plena seca e apresentaram as menores médias de peso aos seis meses, prejudicados pela baixa qualidade dos pastos na época. Aos doze meses, os animais nascidos na primeira metade do ano tiveram as melhores médias de peso, pois completaram um ano nos meses das águas. Os animais nascidos de partos simples foram mais pesados, em todas as idades, que os de partos múltiplos, como se vê na Tabela 1. Outros autores (SILVA et al, 1995; LIMA, 1983; e MACHADO, 1999) também encontraram desvantagens nos produtos de partos múltiplos, mas FERNANDES et al. (1985b) verificaram maior produtividade. Os valores obtidos para partos triplos têm pouco valor, pois baseiam-se somente em três eventos.

O peso ao nascer teve influência positiva sobre os pesos aos 3 e 6 meses, com correlações de $+0,53$ e $+0,59$, respectivamente. Não foi significativa a correlação entre o peso ao nascer e o peso aos 12 meses e nem entre o peso ao nascer e a idade da mãe.

Os ganhos de peso (Tabela 2) refletem o resultado 
Tabela 1 - Médias e desvios-padrão de pesos de ovinos Bergamácia ao nascer e aos 3, 6 e 12 meses de idade $(\mathrm{kg})$

Table 1 - Averages and standard deviations of weights of Bergamasca sheep at birth and 3, 6 and 12 months of age $(\mathrm{kg})$

\begin{tabular}{|c|c|c|c|c|c|}
\hline \multirow[t]{3}{*}{ Item } & & \multirow{2}{*}{\multicolumn{4}{|c|}{$\begin{array}{l}\text { Peso } \\
\text { Weight }\end{array}$}} \\
\hline & & & & & \\
\hline & & $\begin{array}{c}\text { Ao nascer } \\
\text { At birth }\end{array}$ & $\begin{array}{l}3 \text { meses } \\
3 \text { months }\end{array}$ & $\begin{array}{l}6 \text { meses } \\
6 \text { months }\end{array}$ & $\begin{array}{l}12 \text { meses } \\
12 \text { months }\end{array}$ \\
\hline \multirow{3}{*}{$\begin{array}{l}\text { Sexo } \\
\text { Sex }\end{array}$} & Macho & $3,88 \pm 0,96$ & $17,02 \pm 4,96$ & $24,25 \pm 6,18$ & $35,65 \pm 10,05$ \\
\hline & Male & & & & \\
\hline & $\begin{array}{l}\text { Fêmea } \\
\text { Female }\end{array}$ & $3,06 \pm 0,89$ & $15,98 \pm 4,59$ & $22,32 \pm 5,30$ & $31,11 \pm 6,00$ \\
\hline \multirow{4}{*}{$\begin{array}{l}\text { Tipo de parto } \\
\text { Lambing type }\end{array}$} & Simples & $3,88 \pm 0,87$ & $17,23 \pm 4,59$ & $23,86 \pm 3,79$ & $33.32 \pm 8.15$ \\
\hline & Single & & & & \\
\hline & Duplo & $3,06 \pm 0,77$ & $13,24 \pm 3,95$ & $20,31 \pm 14,55$ & $30,50 \pm 6,94$ \\
\hline & $\begin{array}{l}\text { Twin } \\
\text { Triplo } \\
\text { Triple }\end{array}$ & $1,60 \pm 0,58$ & 9,60 & $14,55 \pm 1,91$ & $19,85 \pm 1,63$ \\
\hline
\end{tabular}

verificado nos pesos. Os machos cresceram mais rapidamente que as fêmeas e, em sucessivos intervalos, os ganhos foram decrescentes. As taxas de ganho de peso apresentadas na Tabela 2 foram superiores aos relatados, em extensa revisão, por GATENBY (1986), para ovinos não suplementados, nos trópicos e sub-trópicos, e aos publicados por MACHADO et al. (1999), para mestiços de raças especializadas para corte $\mathrm{x}$ deslanados.

As correlações fenotípicas entre os pesos nas idades estudadas foram positivas e altamente significativas $(\mathrm{P}<0,01)$ - entre peso ao nascer e aos três meses foi de $+0,53$; aos seis meses, $+0,30$; aos doze meses, $+0,22$; entre peso aos três meses e aos seis meses, $+0,77$; aos doze meses, $+0,54$; e entre peso aos seis meses e aos doze meses, $+0,59$.

\section{Mortalidade}

Os níveis de mortalidade foram de $6,62 \%$ do nascimento aos quatro dias (perinatal) e $22,96 \%$ de 5 a 90 dias de idade. A mortalidade inicial foi significativamente influenciada $(\mathrm{P}<0,01)$ pelo ano de nascimento, tipo de parto e peso ao nascer, não sendo aparente nenhum efeito de sexo. Os níveis de mortalidade inicial, ano a ano, não mostraram tendência. Os raros partos triplos resultaram em grande mortalidade, $37,50 \%$. Nos partos simples, a mortalidade inicial dos cordeiros foi de $4,60 \%$ e, nos duplos, $12,60 \%$. Informações sobre mortalidade perinatal são pouco comuns na literatura nacional. COIMBRA FILHO et al.(1979), por exemplo, consignam níveis de 5,60 a $22,20 \%$, de 0 a 3 dias, no Estado do Rio Grande do Sul com cordeiros de raça de lã. GAMA et al. (1991) relataram, em estudo com 16881 cordeiros, nos Esta- dos Unidos, o valor $8,00 \%$ de mortalidade nas primeiras 24 horas após o nascimento.

A mortalidade até 90 dias (desmama) foi influenciada $(\mathrm{P}<0,01)$ pelo ano e mês de nascimento, pela gemelaridade e pelo peso ao nascer. De ano a ano, variou largamente, chegando a $88 \%$ em ano de seca intensa e greve de trabalhadores. Não houve, porém, tendência temporal. Os meses finais do período de seca mostraram as mais altas mortalidades. Cordeiros nascidos de parto duplo morreram mais que os nascidos de parto simples, 42,68 e $25,47 \%$, respectivamente, enquanto os de parto triplo alcançaram a elevada taxa de 62,50\%. COSTA et al. (1990) também constataram grandes diferenças, em mortalidade até a desmama, entre cordeiros nascidos em diferentes tipos de parto na raça Morada Nova, no Estado de São Paulo: simples, $16,30 \%$; duplos, $25,70 \%$; triplos, $72,20 \%$; e quádruplos, 100,00\%. A influência do peso ao nascer pode ser mais bem avaliada comparando-se animais que nascem com baixo peso, menos de $1,5 \mathrm{~kg}$, com os demais. Nos primeiros, a mortalidade até 90 dias de idade foi de $70 \%$ e nos maiores de $1,5 \mathrm{~kg}$, de $28,69 \%$.

Tabela 2 - Ganho de peso diário médio de ovinos Bergamácia em diferentes intervalos $(\mathrm{g})$

Table 2 - Average daily gains at different intervals $(g)$

\begin{tabular}{lcr}
\hline Intervalo, dias & Macho & Fêmea \\
Interval, days & Male & Female \\
\hline $0-90$ & 146,00 & 143,56 \\
$90-180$ & 80,33 & 70,44 \\
$181-365$ & 63,33 & 48,83 \\
$0-180$ & 113,17 & 107,00 \\
$0-365$ & 87,04 & 76,86 \\
\hline
\end{tabular}


Pequena correlação, -0,22, quantificoi a relação entre o peso ao nascer e a mortalidade até a desmama.

A literatura brasileira consigna grandes disparidades entre os níveis de mortalidade até a desmama. Estes índices vão desde $80,60 \%$ verificados por COIMBRA FILHO et al. (1979), em cordeiros nascidos no inverno no Estado do Rio Grande do Sul, passando pelas médias de $25,00 \%$, estimada por COIMBRA FILHO e SELAIVE (1979) para o Estado do Rio Grande do Sul, a 42,00\%, citada por FIGUEIREDO et al. (1979), para ovinos deslanados no Nordeste brasileiro. Há, ainda, valores bem baixos, como os citados por LIMA (1983), 12,90\%, para a raça Santa Inês, e RODA et al. (1995), 11,33 e $13,42 \%$ para raças produtoras de lãs, no Estado de São Paulo. Na literatura estrangeira, constam as estimativas divulgadas por GAMA et al. (1991) para países como Austrália, 15 a 20\%, e Nova Zelândia, $15 \%$, fazendo notar a grande variação das médias em função do ano, da raça e do manejo.

As causas de morte não foram sistematicamente determinadas, mas alimentação deficiente na seca, ataque de predadores, verminoses e pneumonia foram as mais comuns.

\section{Produção de lã}

A média geral de peso de velo, com tosquia anual, foi de $1,28 \mathrm{~kg}$, muito abaixo do valor obtido pela raça Bergamácia em sua origem. No Rio Grande do Sul, COIMBRA FILHO e SELAIVE (1979) informaram que a média de produção de lã, por animal, é menor que $3,0 \mathrm{~kg}$.

KALIL et al. ( 1980) obtiveram médias de pesos de velo variando entre 2,8 e $2,9 \mathrm{~kg}$ para diversas raças estudadas no Estado de São Paulo. A média alcançada neste trabalho está longe de atender ao padrão racial brasileiro (ARCO, 1999), que especifica "a produção de lã em 5,0 kg nos machos e 4,0 kg nas fêmeas".

Houve diferença significativa $(\mathrm{P}<0,05)$ entre os sexos, com médias de $1,43 \pm 0,63 \mathrm{~kg}$ e $1,25 \pm 0,52 \mathrm{~kg}$, respectivamente, para machos e fêmeas. Tiveram influência altamente significativa $(\mathrm{P}<0,01)$ sobre o peso do velo sujo, a idade e o peso na data da tosquia, a ordem da tosquia na sucessão, o peso com um ano de idade e o ano em que foi feita a pesquisa. A correlação entre o peso do velo e o peso do animal foi $\mathrm{de}+0,41$, altamente significativa $(\mathrm{P}<0,01)$. A primeira tosquia teve baixo peso; o peso aumentou na segunda e terceira, voltando ao nível da primeira e se estabilizando daí para diante. OSÓRIO et al. (1983) verificaram que o peso do velo cresce com a idade até tres anos e, daí para diante, fica estabilizado, como neste trabalho. A variação de ano para ano não mostrou nenhuma tendência e, em parte, deve ter sido causada por diferenças nas datas de execução das tosquias.

Os pesos dos velos de sucessivas tosquias foram correlacionados entre si, verificando-se correlação positiva em torno de 0,55 , sendo as menores correlações entre a primeira tosquia e as demais.

A avaliação da qualidade da lã, realizada em dez amostras, no Secretariado Uruguayo de la Lana, classificou o produto como "carpet wool", com diâmetro médio de 38 micra e coeficiente de variação de $43,8 \%$. Outras dez amostras avaliadas na Cooperativa de Lãs Vale do Uruguai produziram as seguintes médias: rendimento 74,9\%, diâmetro 30,8 micra e comprimento $6,4 \mathrm{~cm}$. O padrão racial da raça Bergamácia Brasileira (ARCO, 1999) define a lã como de finura média, de 30 a 31 micra, cruza 2 , de qualidade baixa, enquanto o padrão italiano (ASSOCIAZIONE..., 1984) define somente o diâmetro de 40 a 48 micra.

\section{Conclusões}

A amostra de animais da raça Bergamácia Brasileira, analisada neste trabalho, não atendeu, quanto às características produtivas, aos padrões raciais da Itália e do Brasil. Na reprodução, o rebanho comparou-se às raças deslanadas criadas no Brasil e, quanto aos pesos até 12 meses, as superou. A produção de lã foi baixa e de qualidade inferior. A mortalidade observada foi alta e constituiu o aspecto mais negativo do rebanho. As informações aqui divulgadas poderão ser consideradas em futura revisão do padrão racial brasileiro e na formulação de projetos de criação ou de pesquisas sobre a raça no país.

\section{Referências Bibliográficas}

ASSOCIAÇÃO BRASILEIRA DE CRIADORES DE OVINOS ARCO. 1999. Padrão da raça Bergamácia brasileira. Bagé, RS. 2p.

ASSOCIAZIONE NAZIONALE DELLA PASTORIZIA. 1984. Caratteri tipici e indirizzi di miglioramiento - Razza Bergamasca. Roma, Itália. 6p.

BODISCO, V., DUQUE, C.M., VALLES, A.S. 1973. Comportamento productivo de ovinos tropicales en el periodo 1968 1972. Agron. Trop., 23(6):517-540.

COIMBRA FILHO, A., LEBOUTE, E.M., MORAES, C.M.M. 1979. Influência de duas épocas de nascimento na sobrevivência e desenvolvimento dos cordeiros e na produção de lã das ovelhas. R. Soc. Bras. Zootec., 8(3):448-457.

COIMBRA FILHO, A., SElAIVE, A. 1979. A. Situação e perspectiva da produção ovina no Brasil. Porto Alegre, RS: Embrater. 30p. 
COMBELLAS, J. 1980. Production and reproduction parameters of tropical sheep in improved production systems. Trop. Anim. Prod., 5(3):260-272.

COSTA, M.J.R.P., QUEIROZ, S.A., RIBEIRO, J.L.C. 1990. Avaliação de alguns aspectos do desempenho de ovinos da raça Morada Nova na região de Franca - SP. R. Soc. Bras. Zootec., 19(4):340-346.

FERNANDES, A.A.O., SANDERS, J.O., SHELTON, M. et al. Fatores genéticos e ambientais como fonte de variação no crescimento de cordeiros da raça Morada Nova. In: REUNIÃO ANUAL DA SOCIEDADE BRASILEIRA DEZOOTECNIA, 22, 1985, Camboriú. Anais...Camboriú: SBZ, 1985a. p.174.

FERNANDES, A.A.O., SANDERS, J.O., SHELTON, M. et al. Desempenho produtivo de um rebanho de ovinos Morada Nova no sertão do Ceará. In: REUNIÂO ANUAL DA SOCIEDADE BRASILEIRA DE ZOOTECNIA, 22, 1985, Camboriú. Anais... Camboriú: SBZ, 1985b. p.252.

FERNANDES, A.A.O., BUCHANAN, D.S., CASANOVA, H.S. Efeitos genéticos e de ambiente influenciando crescimento e sobrevivência de cordeiros Morada Nova. In: REUNIÃO ANUAL DA SOCIEDADE BRASILEIRA DE ZOOTECNIA, 30, 1993, Rio de Janeiro. Anais... Rio de Janeiro: SBZ, 1993. p.279.

FIGUEIREDO, E.A.P., OLIVEIRA, E.R., BELLAVER, C. 1979. Performance de ovinos deslanados no Brasil. Centro Nacional de Pesquisas de Caprinos. Circular Técnica 1. 32p.

FIGUEIREDO, E.A.P., SIMPLÍCIO, A.A., LIMA, F.A.M. et al. Estudo comparativo do crescimento de ovinos de diferentes raças no período de aleitamento. In: REUNIÃO ANUAL DA SOCIEDADE BRASILEIRA DE ZOOTECNIA, 22, 1985, Camboriú. Anais...Camboriú: SBZ, 1985. p.247.

GAMA, L.T., DICKERSON, G.E., YOUNG, L.D. et al. 1991. Effects of breed, heterosis, age of dam, litter size and birth weight on lamb mortality. J. Anim. Sci., 69(7):2737-2743.

GATENBY, R.M. 1986 Sheep production in the tropics and subtropics. New York: Longman. 351p.

INSTITUTO BRASILEIRO DE GEOGRAFIA E ESTATÍSTICAIBGE. 1997. Anuário estatístico do Brasil. Volume 57. Rio de Janeiro.

JARDIM, W.R., PEIXOTO, A.M., SILVEIRA FILHO, S. 1956. Estudos sobre o comportamento de ovinos mestiços Romney Marsh em Piracicaba. I. Estação de monta e época de reprodução. Rev. Agric., 31(2):93-106.

KALIL, E.B., SCHAMMASS, E.A., PRUCOLI, J.O. 1980. Repetibilidade do peso do velo em rebanhos do Posto de ovinos e caprinos de Itapetininga, SP. Bol. Ind. Anim., 37(2):233-243.
LIMA, F.A.M. 1983. Desempenho de ovinos deslanados no Nordeste Brasileiro e plano de melhoramento para o futuro. In: SIMPÓSIO INTERNACIONAL DE PRODUÇÃO ANIMAL, 1, Ribeirão Preto, 1983. Anais... Ribeirão Preto, 1983.

MACEDO, F.A.F., MARTINS, E.N., SIQUEIRA, E.R. et al. 1996. Desenvolvimento de cordeiros puros e cruzados terminados em pastagem ou confinamento In: REUNIÃO ANUAL DA SOCIEDADE BRASILEIRA DE ZOOTECNIA, 33, 1996, Volume 1, Fortaleza. Anais...,p. 254-255.

MACHADO, R., SIMPLÍCIO, A.A., BARBIERI, M.E. 1999. Acasalamento entre ovelhas deslanadas e reprodutores especializados para corte: Desempenho produtivo até desmama. Rev. bras. zootec., 28(4):706-712.

RODA, D.S., SANTOS, L.E., CUNHA, E.A. 1995. Peso ao nascer e mortalidade pre-desmame em cordeiros das raças Ideal e Corriedale. Bol. Ind. Anim., 52(1):67-70.

SANTIAGO, A.A., PAULIN NETO, L. 1954. Estudo sobre ovinos Suffolk em São Paulo. Bol. Ind. Anim., 14(único):19-30.

SANTIAGO, A.A., PAULIN NETO, L. 1954a. Observações sobre o comportamento de ovinos da raça Suffolk no Estado de São Paulo. Bol. Ind. Anim., 14(único):3-18.

SAS/STAT. 1990. User's guide, Statistical Edition. Version 6.04. Cary SAS Inst., Inc.

SILVA, F.L.R., FIGUEIREDO, E.A.P., BARBIERI, M.E. et al. 1995. Efeito de ambiente e de reprodutor sobre as características de crescimento e de reprodução em ovinos Santa Inês no Estado do Ceará. R. Soc. Bras. Zootec., 24(4):559-569.

SILVA, F.L.R., ARAÚJO, A.M., FIGUEIREDO, E.A.P. 1998. Características de crescimento e reprodução em ovinos Somali no Nordeste Brasileiro. R. Bras. Zootec., 27(4):1107-1114.

Recebido em: 23/12/99

Aceito em: 17/04/00 